\title{
RETÓRICA, RAZONABILIDAD Y ÉTICA. UN ENSAYO SOBRE PERELMAN
}

\section{Introducción}

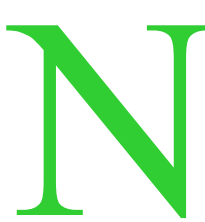

o disponemos todavía de una perspectiva global de la obra de Chaïm Perelman. En vez de ofrecer tal panorámica, nos basta señalar que Perelman experimenta, en términos generales, un profundo cambio que nos permite dividir su obra en dos períodos. Sin embargo, esta afirmación es relativa: el mismo Perelman explica repetidamente lo que en su opinión es la causa de este cambio, a saber, el relativismo extremo al que le lleva su posición sobre la indiscutibilidad de los valores. Sin una síntesis de su trabajo, esta evolución y su explicación sólo podrían describirse muy superficialmente.

El artículo se divide en cuatro apartados. En el primero esbozaremos nuestra hipótesis, incluyendo una interpretación de «razonabilidad». En el segundo apartado, y como introducción al tercero, nos centraremos brevemente en la dimensión hermenéutica de su teoría. El tercer apartado aborda la dimensión filosófica y antropológica que, en nuestra opinión, está presente en la teoría de Perelman. Por consiguiente, vamos a situar nuestra interpretación dentro del esquema más amplio propuesto en la obra de George Herbert Mead. Creemos que la Nueva Retórica puede aclararse a la luz de la teoría del interaccionismo simbólico, tal y como es defendida por G. H. Mead. Los resultados obtenidos mostrarán, en el cuarto apartado, las opciones filosóficas y éticas básicas del pensamiento de Perelman.

Nuestro objetivo en esta contribución es intentar analizar algo más detalladamente la evolución de Perelman. Esto nos permitirá obtener un mayor conocimiento sobre la globalidad de su teoría. Como punto de partida, formularemos una hipótesis sobre esta evolución y sobre su relevancia para la propia teoría de Perelman. 


\section{Perelman I y Perelman II}

En el primer período de su reflexión filosófica, el propósito de Perelman era desarrollar una teoría que le permitiera formular proposiciones objetivas sobre conceptos «prestigiosos» o «confusos». La pluralidad de concepciones que pueden cubrirse con tales conceptos es una objección seria a la consecución de un consenso sobre el significado de los mismos. Esto es resultado de que los conceptos prestigiosos o confusos -como «justicia»- están cargados emotivamente de manera muy fuerte. Esta carga emotiva implica una escala de valores que está representada por cada una de las posibles concepciones y que no se refiere necesariamente -y en la mayoría de las ocasiones, en absoluto- a un consenso. En ausencia de tal consenso o prueba, un filósofo se ve obligado a formular proposiciones objetivas de tal manera que, dadas diferentes opiniones en el nivel de las concepciones, pueda encontrarse un consenso más allá de éste, en el nivel de un concepto.

Puede advertirse que aquí se encuentra el primer punto de conexión con la obra posterior de Perelman: el hecho de que, en el primer período, el propósito de este filósofo era alcanzar un consenso. Esta idea no está exenta de problemas, porque cuanto más amplio sea un consenso, menos concreto será su contenido. En el análisis del concepto de justicia, por ejemplo, la formulación de la justicia formal se presenta como una descripción definitiva de todas las posibles concepciones de la justicia. Por un lado, esta formulación dice que los iguales deben ser tratados igualmente. Debemos recordar que esta idea no es específica del razonamiento jurídico; es igualmente válida para todas y cada una de las formas de razonamiento teórico y práctico que operan con reglas. Y, por otro lado, la fórmula de la justicia formal tiene un significado especial en el pensamiento jurídico, puesto que cubre todas las posibles concepciones de justicia.

Un segundo punto de conexión entre el primer y segundo Perelman se refiere a la relación entre razón teórica y razón práctica. En el primer período, los criterios de comprobación lógica o empírica (razón teórica) eran también criterios vinculantes para la razón práctica. En el segundo período esta relación se invierte; los criterios del razonamiento práctico se convierten, en la Nueva Retórica, en paradigmas del razonamiento teórico. A partir de entonces se tiene conciencia de que la ciencia no puede, por ejemplo, demostrar sus propios axiomas fundamentales, sino que está fundada en paradigmas (provisionales), que operan como una matriz para las actividades de resolución de problemas dentro de esa ciencia. En realidad, la imposibilidad de verificar un paradigma es similar a la imposibilidad de verificar las proposiciones valorativas. Esto significa que, en vez 
de aplicar los criterios de racionalidad teórica a la razón práctica, se realiza más bien la operación contraria.

Se consideraba que la fórmula de la justicia formal era lógicamente neutral. Sin embargo, Perelman pronto se da cuenta de que esta neutralidad lógica deja abierta la puerta a opciones profundamente inmorales. Estas opciones, como han mostrado los horribles ejemplos de la ocupación nazi, serían incapaces de producir consenso.

La originalidad de la Nueva Retórica descansa, entonces, en el hecho de que la «neutralidad lógica» y el «consenso» son conducidos conjuntamente a un tronco común: la «aceptación».

El centro del nuevo punto de partida epistemológico de Perelman es la sustitución del requisito de prueba de la racionalidad de las proposiciones valorativas, por el requisito de la «aceptación». Se considera necesario aceptar proposiciones que son evidentes (por ejemplo, las deducciones lógicamente correctas); a la inversa se sigue que uno puede, pero no necesariamente tiene que, aceptar proposiciones que no son evidentes. La oposición entre «aceptación necesaria» y «aceptación no-necesaria» -esta última es la propia en las proposiciones valorativas- puede ser eludida una vez que se supera la distinción entre «necesario/no-necesario» como «differentia specifica» para la racionalidad. De este modo, Perelman centra su atención en lo que tienen en común la aceptación necesaria y la no-necesaria, esto es, la «aceptación». Mediante la idea de «aceptación», las proposiciones evidentes y las no-evidentes se mantienen unidas en un continuo bipolar. Lo que es evidente es, por ello, racional; pero lo que no es evidente no está, por esta sola razón, privado de racionalidad.

En un límite (interno) del continuo que mantiene unidas las proposiciones evidentes y las no-evidentes, encontramos la «evidencia», que implica aceptación necesaria. En el otro límite (externo) del continuo encontramos una aceptación puramente emocional, la cual, precisamente por estar basada en la emoción, no pretende ser racional. La sustitución del requisito de prueba por el de aceptación supone que, a partir de ahora, la razón práctica no se subordina a la razón teórica. Gracias a esta nueva perspectiva, la razón teórica y la razón práctica ya no están separadas. La diferencia entre las proposiciones teóricas y las prácticas se convierte en una cuestión de grado entre la aceptación necesaria y la no-necesaria, y esta diferencia se expresa en los términos «racional» $\mathrm{y}$ «razonable». Perelman escribe que:

«El primer aspecto se refiere a lo que hay de necesario, de demostrable; el segundo se refiere a lo que hay de argumentativo y de no necesario en la razón». (Perelman, 1970, 294). 
El enfoque novedoso de la Nueva Retórica consiste en que no se pretende, prioritariamente, encontrar una verdad demostrable sino, más bien, «razonabilidad». La razonabilidad es el objetivo de la aceptación. De acuerdo con el tipo de discurso («persuasivo» o «convincente», diferencia que se enlaza con el tipo de auditorio al que se dirige el discurso -auditorio «particular»o «universal»-), intentaremos ahora analizar cómo puede entenderse la «razonabilidad».

Un discurso razonable pretende obtener la aceptación de las personas razonables que forman parte del auditorio universal. Se supone que aquéllos que pertenecen a este auditorio aceptan únicamente las proposiciones razonables. Esta manera de presentar las cosas es innegablemente circular, pero ello es una consecuencia inevitable de la ausencia de criterios a priori de razonabilidad en la teoría de Perelman. En cambio, algunos estudiosos piensan que es demasiado vaga como criterio (Villey, 1969, 101; Legros, 1980, 45). En otro artículo he escrito que la idea de racionalidad comporta una fuerte concepción sociológica (Wintgens, 1987). Tal concepción de racionalidad presupone que las ideas fácticas también tienen un valor normativo.

Sin embargo, una mirada más detallada muestra que tal interpretación desvirtúa las ideas más provechosas que se encuentran en la teoría de Perelman. Un argumento a favor de esto último podría ser el siguiente:

Sin un criterio a priori de razonabilidad, nadie puede ser considerado irrazonable a priori; esto sería una contradicción. Por ello toda persona debe considerarse razonable hasta que no se demuestre lo contrario. Esta interpretación está de acuerdo con la concepción de Perelman de que el auditorio universal no es un auditorio de élite. Por otro lado esta interpretación evita una concepción sociológica, porque no toda persona forma parte del auditorio universal sin mayor cualificación.

En relación con esto puede notarse que, en la búsqueda de una lógica de valores a la que conduce la Nueva Retórica, permanecen claramente rasgos del pensamiento anterior de Perelman. Si la demostración de las proposiciones valorativas es aún imposible, en la Nueva Retórica esta imposibilidad ya no se considera problemática. Por otro lado, la evolución que lleva a cabo Perelman no es tan radical como pudiera parecer a primera vista.

En efecto, la fórmula de justicia formal y el mecanismo estructural real de la argumentación son básicamente similares. En realidad, la fórmula de justicia formal reaparece en la Nueva Retórica bajo la forma del principio de «inercia». Este principio implica que la conformidad con los precedentes se considera racional (Perelman, 1970, 
298) y, como consecuencia de ello, la conformidad con los precedentes no tiene que ser justificada. En cambio, una desviación de los precedentes sí debe ser justificada (Perelman, 1976c, 198). En este principio se reconoce la fórmula de justicia formal, según la cual los iguales tienen que ser tratados igualmente. Es más importante el hecho de que el principio de inercia también permite una desviación de las reglas o precedentes, a condición de que ésta sea justificada.

Más adelante nos ocuparemos de nuevo de este asunto en relación con la filosofía de Perelman. Basta decir aquí que, de acuerdo con las observaciones que hemos hecho, es posible desviarse de la aplicación estricta de la regla respetando la fórmula de justicia formal. Esto implica lógicamente que un argumento basado en una concreta concepción de la justicia podría tener una justificación racional.

El punto central de nuestra interpretación de la obra de Perelman es la relación entre lo que llamamos el núcleo estricto de razonabilidad y la estructura de la argumentación. En las dos próximas secciones nos detendremos en ello.

3. El punto de vista hermenéutico: la preponderancia del auditorio interno y la estructura de la argumentación

La argumentación retórica -el tipo de argumentación que desarrolla Perelmanmuestra una diferencia específica con otros tipos de argumentación: su relación con un auditorio. Un orador se dirige a un auditorio con la intención de convencer o persuadir a sus miembros. El propósito común de ambas formas de discurso es obtener o incrementar la aceptación del auditorio.

Perelman distingue entre diferentes tipos de auditorio. En primer lugar, encontramos el auditorio consistente en una persona deliberando consigo misma. Esto es lo que llamaremos el «auditorio interno». En segundo lugar, encontramos el auditorio universal, que contiene a todas las personas razonables. La relación entre estos dos tipos de auditorio es que el auditorio interno es una forma particular del universal (Perelman, 1976a, 54). De hecho, en la deliberación orador y auditorio pueden comprobar la razonabilidad del discurso. La idea del auditorio puede ahora unirse a la interpretación que dábamos antes de la «razonabilidad». Si cada persona es considerada razonable (mientras que no se demuestre lo contrario), entonces cada persona se supone capaz de sostener un discurso interno. En este discurso el «otro» parece representar un punto de vista normativo, porque el «otro» se considera como la encarnación de la razonabilidad.

La manera específica en que la razonabilidad se presenta a sí misma en el auditorio interno puede explicarse mejor si tomamos en 
cuenta las ideas de persona y de identidad presentadas por George Herbert Mead. Parece como si Mead ya representara lo que después se llamaría un punto de partida «hermenéutico» en las ciencias sociales. Una perspectiva hermenéutica es aquélla en la que la conducta humana se explica a través de una interpretación del significado que tiene para los actores mismos (Mac Cormick, 1981, 29). En otras palabras, la explicación de la conducta contiene el punto de vista de los actores.

En términos de la teoría de Perelman, esto significa que no sólo puede analizarse lo externo y observable (la realidad del discurso, las reacciones visibles del auditorio, etc.), sino también el modo en que se llega a la «aceptación». No hay, sin embargo, muchas indicaciones en el trabajo de Perelman concernientes al funcionamiento del auditorio interno. Para aclarar las ideas sobre esto, creemos que sería interesante tener una panorámica más completa del trabajo de Mead, el padre fundador del interaccionismo simbólico. Esto nos permitirá entender mejor la dimensión hermenéutica de la teoría de Perelman.

Antes de esto, señalaremos brevemente los principales puntos de la propia teoría de Mead. La estrategia de este enfoque se basa, en primer lugar, en una idea no desarrollada del propio Perelman: que su concepto de razonabilidad se refiere a una antropología (Perelman, 1976d, 72). En segundo lugar, se basa también en algunas observaciones de un autor que sostiene que podemos encontrar una dimensión psico-social implícita en la teoría de la argumentación de Perelman, o que esta teoría presupone una forma de explicación psicológica (Apostel, 1963). El mismo autor analiza la teoría de Perelman a través de las teorías del equilibrio cognoscitivo, de las dinámicas de grupo, etc. (Apostel, 1963). Creemos, sin embargo, que es posible otra perspectiva fructífera: utilizar las aportaciones de la teoría del interaccionismo simbólico.

4. Componentes filosóficos y antropológicos de la Nueva Retórica: una comparación con el trabajo de George Herbert Mead

La aportación más importante de Mead a la estructura de la conciencia consiste en la idea de que la conciencia humana no es algo dado que puede ser presupuesto en la explicación de la conducta humana (Mead, 1974, 189 y 223). No es la conciencia individual, sino la sociedad la que es lógicamente anterior (Mead, 1974, 189 y 223).

En la sociedad los individuos interactúan. La interacción interindividual es comunicación en la medida en que el «significado» se 
transmite. Pero de nuevo, así como la conciencia no es dada, el significado tampoco lo es. Ocurre, más bien, que el significado surge a través de la comunicación, concretamente a través de la «comprensión» entre los participantes en la interacción.

La conciencia y el significado, como elementos del proceso comunicativo, tienen una mutua relación especial. La conciencia se origina en la medida en que los participantes en la interacción son capaces de incorporar la reacción de otros en sí mismos (Mead, 1974, 63 y 67). Este es, por excelencia, el caso del lenguaje humano, en el que un orador puede escucharse a sí mismo mientras habla y al mismo tiempo observar las reacciones de su auditorio. Como veremos a continuación con algo más de detenimiento, éste es el primer punto en el que coinciden Perelman y Mead.

Debido a nuestra capacidad para asumir el papel del orador y el del auditorio podemos, mientras hablamos, imaginarnos a nosotros mismos tal como lo hace nuestro auditorio. Podemos, al menos implícitamente, hacernos con la reacción de los otros. Cuando hacemos esto, cuando conversamos con nosotros mismos por medio de símbolos significativos, pensamos (Mead, 1974, 47, 186 y 260).

Pensar es una operación de nuestra «mente». Puesto que según Mead cuerpo y mente no están separados, las mentes no empiezan a pensar a partir de la nada. Esto es así porque el significado no es algo dado, y la comunicación es algo más que una transmisión de significados preexistentes, lo que implica que la mente es el foro preexistente donde ocurren las cosas físicas. Mead guarda cuidadosamente la distancia con la teoría de Descartes de las ideas innatas y con su dualismo. En primer lugar, sostiene que pensar sólo es posible en términos de símbolos significativos (Mead, 1974, 268) que surgen a través de la interacción. Mead sostiene acertadamente que el significado o sentido es siempre significado compartido. Los términos con los cuales se piensa son siempre portadores de sentido compartido. En segundo lugar, Mead lleva a extremos más radicales su punto de partida con la tesis de que la mente no sólo opera en términos de significado social, sino que no puede operar de otra manera (Mead, 1974, 222). Esta radicalización contiene toda la crítica de Mead al sustancialismo cartesiano.

Consecuencia de todo esto es que la interacción precede al pensamiento. La interacción es, por tanto, lógicamente anterior al pensamiento. Para concluir este punto, Mead dice que lo mental sólo puede emerger y operar a través de la interacción (Mead, 1974, 51). Esto significa que Mead puede saldar las cuentas con la separación cartesiana entre cuerpo y mente, entre mente y comunicación.

El proceso de comunicación del cual surge el significado provoca, al mismo tiempo, la aparición de lo mental (Mead, 1974, 133), 
dado que los mecanismos de creación de significado ya están inmersos en un acto social antes de que surja una idea (Mead, 1974, 112). La conciencia o el «reconocimiento de significado» es el siguiente paso en la formación de lo mental. De nuevo, la conciencia no es, como lo mental, algo dado, sino el resultado de una interacción.

Hasta ahora nos hemos centrado en la cuestión de cómo «mente» y «conciencia» surgen de la interacción. Ahora queremos analizar más profundamente la actividad de la mente, es decir, el pensamiento.

La comunicación por medio de símbolos significativos implica que el significado es siempre significado compartido, porque el significado de los símbolos deriva de la respuesta de los otros. Sin embargo, sería erróneo suponer que pensar en términos de símbolos significativos se adecúa a las propiedades particulares de las cosas. Para explicar el proceso del pensamiento, Mead introduce una forma específica de respuesta, el «reconocimiento» (Mead, 1974, 84). Un estímulo es particular, una respuesta es universal. Un concepto universal es un concepto cuyo significado es -como en el caso de un concepto particular- social. Un concepto surge en el individuo que se pone a sí mismo en el lugar de otros individuos en relación con un cierto asunto. Las distintas perspectivas posibles que pueden ser adoptadas por individuos diferentes son, en algunos puntos, idénticas. Es precisamente esta identidad la que constituye el rasgo distintivo de la universalidad, el núcleo de este concepto. Y es precisamente porque los individuos son capaces de ponerse a sí mismos en el lugar de otros por los que son capaces de pensar, es decir, de usar conceptos universales.

Siguiendo esta línea, Mead realiza otra distinción entre «yo»y «me» [《I» and «me»]. Todos los otros individuos tienen, desde sus distintas perspectivas, una actitud hacia un objeto. Esta actitud es, en algunos aspectos, compartida por los demás. Cada individuo incorpora a sí mismo esta actitud compartida, y el resultado de esta incorporación es lo que Mead llama «el otro generalizado» (Mead, 1974, 90). Este «otro generalizado» es lo que significa el componente «me» de la personalidad. Frente a este aspecto social de la identidad de los individuos se sitúa el componente «yo», la única parte impulsiva y espontánea de la persona. «Yo» $\mathrm{y}$ «me» interactúan como aspectos personal y social de la personalidad. El pensamiento de mí mismo es, en opinión de Mead, condicionado por el pensamiento de «me» como una identidad socialmente condicionada, aunque es precisamente compensado por alguna influencia personal suministrada por el «yo». 


\section{Consecuencias para nuestra interpretación de la teoría de Perelman}

La originalidad de la teoría de Mead se encuentra en el hecho de que se separa del sustancialismo cartesiano. Subraya el punto de que la edificación y el funcionamiento de la conciencia presuponen procesos idénticos. Más concretamente, la comunicación observable externamente presupone una forma de comunicación interna, que es la que encontramos en la teoría de Perelman como deliberación del sujeto consigo mismo. Interpretándolo a la luz de la teoría de Mead, la encarnación del auditorio universal en el auditorio interno se lleva a cabo en el compañero de deliberación y, de hecho, éste es sólo la internalización de otros en nosotros mismos. En realidad, hay dos puntos importantes dignos de atención. El primero tiene que ver con el modo en que los sujetos deliberan consigo mismo y con los otros, y con la relación estructural entre estas formas de deliberación. El segundo se ocupa de la relación entre razonabilidad (como la hemos presentado aquí) y argumentación.

Las aportaciones de Mead referentes a la estructura de la personalidad como una combinación de aspectos «yo» $\mathrm{y}$ «me» pueden contribuir a nuestra aproximación a Perelman de la siguiente manera. En primer lugar, un orador que expresa proposiciones que cree razonables ha llevado a cabo una deliberación consigo mismo, un diálogo entre el otro generalizado y su «yo». Puede suponerse que, al menos parcialmente, el otro generalizado (aun incluyendo las reacciones concretas del auditorio) inspira la opinión del orador sobre el auditorio que está frente a él. Esto está de acuerdo con la tesis de Perelman de que el auditorio es una construcción del orador. Pero, tal como nosotros lo entendemos, esta construcción es cualquier cosa menos una fantasía. Existe, por así decirlo, una relación recíproca entre el auditorio y el orador, que se manifiesta ante todo en la mente de éste último. Un proceso similar se desarrolla en los miembros del auditorio. Como un compuesto de individuos $(1,2, \ldots, n)$, es un conjunto de personalidades, cada una de las cuales tiene una identidad «yo» $\mathrm{y}$ «me». Las reacciones del auditorio son, por tanto, entendidas como reacciones de personalidades después de deliberar con ellas mismas. De nuevo, la interacción entre «yo»y «me» en la mente de los sujetos determinará el resultado de la argumentación: la aceptación o el rechazo de las afirmaciones del orador. Y este resultado será nuevamente integrado en la concepción que el orador tiene sobre el otro generalizado. En esta perspectiva dinámica de la argumentación se advierte que el modo en el que el orador y el auditorio intervienen en el desarrollo de la argumentación es, por así decirlo, estructuralmente idéntico; es decir, las reacciones del auditorio 
en el orador y viceversa están enlazadas a una forma de identidad estructuralmente similar.

La segunda idea en la que queremos detenernos es la relación entre razonabilidad y argumentación. Como ya hemos sostenido, no existen criterios a priori para la razonabilidad. Lo que ocurre es, más bien, que la razonabilidad surge a través del discurso, sostenida por la deliberación interna. Sin embargo, este concepto evolutivo de razonabilidad está lejos de ser relativista. Al contrario, creemos que incluye una justificación teórica del núcleo infranqueable de la subjetividad humana. La subjetividad individual, esencialmente unida a la existencia de los otros, no se confunde con ellos, sino que, al contrario, preserva un núcleo de individualidad a través de su existencia social. La conciencia moral del individuo implica la existencia y el reconocimiento de los otros como actores moralmente independientes. Como ser social por excelencia, el individuo social no puede existir de otro modo que constituido por una forma de individualidad que encuentra su origen en, pero que al mismo tiempo aparece como un límite de, lo social.

Se ha criticado a Perelman el que su teoría acepta demasiado fácilmente la idea liberal de los derechos humanos (Haarscher, 1986, 226). Junto a las observaciones hechas hasta ahora, puede sostenerse la posición de Haarscher. Pero una vez puesta en relación con la estructura del auditorio interno, sería más correcto decir que la teoría de Perelman es, de hecho, capaz de conceptualizar esa individualidad infranqueable del sujeto. Haarscher no parece negar que la Nueva Retórica incorpore una dimensión ética, sino que afirma que esta dimensión es fundamentalmente un a priori no reflejado en la teoría de Perelman. Debido a estos valores implícitos en la Nueva Retórica pensar en términos de razonabilidad en vez del razonamiento matemático convierte al Derecho en una disciplina ejemplar para la filosofía.

Sin embargo, tal análisis reduce excesivamente la dimensión normativa de la teoría de Perelman, en la cual el aspecto «yo» de las personalidades humanas desempeña un papel esencial y apuntala la teoría de la argumentación. Está fuera de toda duda que, en la teoría de la argumentación, uno se encuentra con las libertades clásicas, entre las cuales las libertades de opinión y de expresión son las más importantes. Además, es cierto que ninguna teoría de la argumentación funcionaría correctamente sin una garantía de esas y otras libertades. Pero en nuestra opinión, esas libertades no tienen que ser aceptadas acríticamente sino que, tal y como muestra nuestra interpretación, puede darse de ellas una explicación teórica. Debido a que estas libertades forman parte de una visión más amplia del hombre, una visión que se conceptualiza en la Nueva Retórica, la búsqueda 
argumentativa de la razonabilidad en el Derecho puede funcionar como un paradigma de la razonabilidad en general.

De acuerdo con nuestra interpretación del individuo como un ser social, Perelman inserta su idea en una perspectiva que toma a los derechos humanos, filosóficamente hablando, en serio. La dimensión comunicativa de esta teoría nos permite situar a esos derechos humanos en un esquema en el que pueden fundarse, a través de su efectividad, en el proceso de comunicación. En este proceso comunicativo, la libertad de opinión y de expresión desempeña un papel fundamental, no como algo dado a priori, sino como una condición necesaria y un vestigio de una concepción en la que la comunicación ocupa un lugar central.

Si la comunicación es una condición esencial para la formación de la conciencia -tal como vimos en la obra de Mead-, ésta, como una huella indeleble, es también una condición necesaria para que opere esta forma de comunicación entre individuos libres.

Partiendo de todo esto, parece claro que la visión ética de Perelman sobre el hombre no está completamente cubierta por una concepción pluralista de los valores. Si esto fuera así, esta interpretación llevaría a la teoría de Perelman hacia el relativismo práctico, en el cual la tolerancia es una condición absoluta y necesaria. Al mismo tiempo, esta condición hace inconsistente al relativismo.

Sin embargo, en nuestra interpretación, la visión ética de Perelman sobre el hombre se refiere más bien a una condición para la concepción pluralista de los valores, una concepción en la cual pueden defenderse distintas posiciones sobre las cuestiones prácticas. Esto implica que la teoría de Perelman introduce, tomando en cuenta las premisas que subyacen a la misma, un metanivel, un nivel más allá del cual no se puede argumentar.

\section{Resumen y conclusión}

En esta breve contribución a la obra de Perelman, hemos intentado ofrecer un esbozo la evolución de Perelman, un análisis que nos permite ver algunas líneas de continuidad entre su primer y segundo período. A continuación presentamos nuestra interpretación de la razonabilidad defendida en la Nueva Retórica. En ausencia de cualquier criterio a priori de razonabilidad, sostuvimos que cada persona debe considerarse razonable hasta que no se demuestre lo contrario. Intentamos después formular una interpretación de la llamada «deliberación del sujeto consigo mismo», en los términos de la teoría del interaccionismo simbólico sostenida por Mead. Esto nos llevó a la conclusión de que las premisas subyacentes a la Nueva Retórica 
conforman una visión ética del hombre como persona autónoma con libertades básicas.

\section{BIBLIOGRAFÍA}

Apostel, L.: 1963, «Rhétorique, psycho-sociologie et logique», en La théorie de l'argumentation-perspectives et applications, Nauwlaerts, Lovaina/París, 263-314.

Haarscher, G.: 1986, «Après Perelman», en G. Haarscher y L. Ingber (eds.), Justice et argumentation, Ed. Univ. Brussels, Bruselas, 223-228.

Legros, R.: 1976, «A propos de 'logique juridique' de Ch. Perelman», (73) Logique et Analyse, 33-51.

MacCormick, N.: 1981, Hart, en W. Twining (ed.), Jurists: Profiles in Legal Theory, Arnold, Londres.

Mead, G. H.: 1974, Mind, Self and Society from the Standpoint of a Social Behaviourist, Univ. of Chicago Press, Chicago/Londres.

Perelman, C.: 1970, «L'idéal de rationalité et la règle de justicie», en Le champ de l'argumentation, Travaux de la Faculté de Philosophie et Lettres, P.U. Brussels, Bruselas, 287-336.

Perelman, C.: 1976 a, Traité de l'argumentation. La nouvelle rhétorique, Ed. Univ. Brussel, Bruselas.

Perelman, C.: 1976 b, Logique juridique - nouvelle rhétorique, Dalloz, París.

Perelman, C.: 1976 c, «Ce que la philosophie peut apprendre par l'étude du droit», en Droit, Morale et Philosophie, L.G.D.J., París, 191-202.

Perelman, C.: 1976 d, «Peut-on fonder les droits de l’homme», en ibíd., 67-73.

Villey, M.: 1969, «La nouvelle rhétorique et le droit naturel», en Critique de la pensée juridique moderne - douze autres essais, Dalloz, París, 85-103.

Wintgens, L.: 1987, «La nouvelle rhétorique et le droit», en La philosophie à 1'épreuve du phénomène juridique: droit et loi. Actes du 5ième colloque de l'Association française de philosophie $d u$ droit, P.U. Aix-en-Provence, Aix-en-Provence, 139-150.

(Trad. de Isabel Lifante) 